\title{
Effects of Seed Moisture Content, Cooking Time, and Chamber Temperature on Nuña Bean (Phaseolus vulgaris L.) Popping
}

Jesse Vorwald ${ }^{1}$ and James Nienhuis ${ }^{2,3}$

University of Wisconsin-Madison, Department of Horticulture, 1575 Linden

Drive, Madison, WI 53706-1590

Additional index words. popping beans, nuñas, postharvest, Andean, popping percentage

Abstract. Nuña beans are a type of common bean (Phaseolus vulgaris L.) native to the Andean region of South America that possess the unusual property of popping; however, little is known regarding postharvest environmental effects on popping. Seed of a photoperiod-insensitive, temperate-adapted nuña bean breeding line, 'PB24', was produced at the Arlington Agricultural Research Station, Arlington, WI, and evaluated in a hot air popper. The experimental design was a factorial with three levels of popping time $(60,90$, and $120 \mathrm{~s})$, five levels of chamber temperature $\left(101,146,208,244\right.$, and $\left.268{ }^{\circ} \mathrm{C}\right)$, and eight levels of seed moisture $(2.5 \%, 3.2 \%, 5.2 \%, 6.6 \%, 8.3 \%, 12.0 \%, 15.3 \%$, and $\mathbf{2 0} \%$ ). Percentage of popped seed, sufficiently expanded to shed the seedcoat, was calculated. A curvilinear decrease in popping percentage was observed with increasing seed moisture content. In contrast, a curvilinear increase in popping percentage was observed with increasing chamber temperature and popping time. Larger mean squares were observed for main effects and first-order interactions associated with seed moisture content and chamber temperature compared with popping time. A combination of seed moisture below $5 \%$, popping chamber temperature of $244^{\circ} \mathrm{C}$, and popping time of $90 \mathrm{~s}$ resulted in popping percentages greater than $90 \%$.

Nuña beans are a type of common bean (Phaseolus vulgaris L.) native to the Andean region of South America that possess the unusual property of popping when exposed to heat (National Research Council, 1989). Popped nuñas are a snack food similar to popcorn; however, the popping mechanism is different. In popcorn, the endosperm is liquefied and explosive pressure builds up in the pericarp (Hoseney et al., 1983); in contrast, popping in nuña beans is the result of pressurized steam trapped within and between the mesophyll cells in the cotyledons (Spaeth et al., 1989). The popped product is an expanded seed with a texture and flavor often

Received for publication 27 May 2008. Accepted for publication 30 July 2008 .

This research was supported by the Wisconsin Department of Agriculture, Trade and Consumer Protection Agricultural Development and Diversification Grant Program (WDATCP Contract No. 17076).

We thank Michell Sass, Felix Navarro, and Kenneth Kmiecik for their preliminary work on this project and for technical assistance. We also thank James Holub for his assistance in the modification of the hot air popper.

This manuscript is a portion of the thesis submitted by Jesse Vorwald in fulfillment of the requirements for an M.S. degree in Horticulture.

${ }^{1}$ Graduate Research Assistant.

${ }^{2}$ Professor

${ }^{3}$ To whom reprint requests should be addressed; e-mail nienhuis@wisc.edu. described as being similar to roasted peanuts. Nuñas are a traditional snack food in the Andean region of South America where they are commonly sold by street vendors or prepared in the home. Popping of nuña beans is a more efficient way of preparing bean protein at high altitudes compared with boiling, which requires larger amounts of fuel (National Research Council, 1989; van Beem et al., 1992; Zimmer, 1992). In the Andean region, nuña beans are popped on hot stones or in hot sand; however, nuña beans can also be successfully popped in a microwave oven or using hot oil or hot air (Tohme et al., 1995).

In popcorn, a seed moisture content above or below an optimum range will dramatically reduce popping percentage (Hoseney et al., 1983). In previous collaborative research on nuña bean popping with Dr. Robert Lindsey, Department of Food Science University of Wisconsin-Madison, Madison, WI, we observed that low-moisture nuña beans (less than 5\% seed moisture) tend to have greater seed expansion after popping compared to seeds with a higher moisture content. The effects of seed production or postharvest environments on nuña bean popping was illustrated in our laboratory in 1996, when nuña seed from a winter nursery increase in Bolivia did not pop; nevertheless, seed produced from progeny grown the next summer at Hancock Agricultural Research Station (ARS), Hancock, WI, did pop. Similar observations were made in the summer of 1996 when differences in seed popping per- centages among an array of inbred nuña bean lines produced in three different locations, Fort Collins, CO, Frutilla, CO, and Hancock, WI, were inconsistent (Dr. Mark Brick, Colorado State University, Fort Collins, CO, personal communication). Differences in moisture content of seed produced at the three locations were unknown; nevertheless, observations from other preliminary experiments indicated that popping performance of nuña beans was related to the moisture content of seeds (Kmiecik and Nienhuis, 1998). To evaluate among nuña bean breeding lines and germplasm accessions, knowledge is needed regarding the effects of postharvest environments on popping performance. The objective of this research was to determine the optimal levels of seed moisture content, popping time, and chamber temperature on the popping percentage of nuña beans.

\section{Materials and Methods}

Plant material. Seed of a photoperiodinsensitive, temperate-adapted inbred nuña bean breeding line, 'PB24', was produced during the 1997 growing season at the Arlington ARS, Arlington WI, using standard cultural practices (Binning et al., 1995). The breeding line 'PB24' was developed using inbred-backcross breeding followed by pedigree selection using the nuña landrace 'Ayachucho' as the donor parent and 'Stockbridge Indian Bean' as the recurrent parent (Kmiecik and Nienhuis, 1997). The seed was harvested at full maturity, stored at ambient room temperature for 4 years, and, before initiation of the present research, dried in a forced air oven at $50{ }^{\circ} \mathrm{C}$ for 3 weeks to $\approx 4 \%$ moisture (Tector Sinar ${ }^{\mathrm{TM}}$ Farmpro 6090 Moisture Analyzer; Sinar Technology, Berkshire, U.K.).

Experimental design. The experimental design was a factorial with three levels of popping times $(60,90$, and $120 \mathrm{~s})$, five levels of chamber temperature $(101,146,208,244$, and $268^{\circ} \mathrm{C}$ ), and eight levels of seed moisture content $(2.5 \%, 3.2 \%, 5.2 \%, 6.6 \%, 8.3 \%$, $12.0 \%, 15.3 \%$, and $20 \%$ ). The experiment was replicated four times.

Popping time. The range of popping times was chosen to reflect times used in prior popping experiments (Kmiecik and Nienhuis. 1997, 1998; Lindsey, Department of Food Science University of Wisconsin-Madison, Madison, WI, personal communication).

Popping chamber temperature. A Presto Hot Air Popper model 04821 (National Presto Industries, Inc., Eau Claire, WI) was modified into a variable-temperature popper. A variable transformer was placed in series with the main heating coil and was bypassed using a three-way switch for maximum power. The range of chamber temperatures was measured with a mercury thermometer placed $5 \mathrm{~cm}$ from the bottom of the popping chamber. The range of temperatures was chosen between the boiling point of water and the maximum setting of the hot air popper at $\approx 50{ }^{\circ} \mathrm{C}$ increments. 
Seed moisture. One-gallon glass Quantpro jars (Fisher Scientific, Pittsburgh, PA) with a sample support made from an inverted $9-\mathrm{cm}$ plastic pot with the bottom removed and a piece of rigid plastic mesh to separate the seed from the salt solution was used as a moisture chamber. Seven saturated salt solutions and a control without a salt solution were used to produce seed moisture levels of $2.5 \%, 3.2 \%, 5.2 \%, 6.6 \%, 8.3 \%, 12.0 \%$, $15.3 \%$, and $20 \%$ (Bell and Labuza, 2000; McCurdy et al., 1980; National Institute of Standards and Technology, 2000a, 2000b; Weston and Morris, 1954). A random sample of 50 seeds was packaged in individual 3inch $\times 4$-inch plastic mesh bags (Vilutis \& Co., Inc., Frankfort, IL). Sixteen bags of 50 seeds were placed in each of the eight moisture chambers, 15 bags for popping

Table 1. Analysis of variance and orthogonal polynomials associated with the factorial effects of seed moisture content, popping chamber temperature, and popping time on popping percentage of nuña breeding line 'PB24'.

\begin{tabular}{lrrc}
\hline & \multicolumn{3}{c}{ Popping percentage $^{\mathrm{z}}$} \\
\cline { 3 - 4 } Source & df & squares & \\
Squnificance \\
\hline Repetitions & 3 & $1,015.6$ & $* * *$ \\
Seed moisture (SM) & 7 & $19,918.7$ & $* * *$ \\
$\quad$ SM linear & 1 & $10,072.2$ & $* * *$ \\
SM quadratic & 1 & 654.5 & $* * *$ \\
SM cubic & 1 & 133.5 & NS \\
Chamber & 4 & $22,720.3$ & $* *$ \\
temperature (CT) & & & \\
$\quad$ CT linear & 1 & $84,088.0$ & $* * *$ \\
CT quadratic & 1 & 0.4 & N \\
CT cubic & 1 & $5,749.7$ & $* * *$ \\
Pop time (PT) & 2 & 825.8 & $* *$ \\
PT linear & 1 & $1,299.7$ & $* * *$ \\
PT quadratic & 1 & 351.9 & $*$ \\
SM $\times$ CT & 28 & $4,063.2$ & $* * *$ \\
SM $\times$ PT & 14 & 292.2 & $* *$ \\
CT $\times$ PT & 8 & 649.7 & $* * *$ \\
SM $\times$ CT $\times$ PT & 56 & 210.4 & $* * *$ \\
Pooled error & 357 & 95.1 & \\
\hline
\end{tabular}

${ }^{\mathrm{z}}$ For purposes of the analysis of variance, popping percentage data were transformed to $\operatorname{arcsine} e^{-1}$.

y***,**,*, and Ns indicate significance at $P \leq$ $0.001,0.01,0.05$, and nonsignificant, respectively.

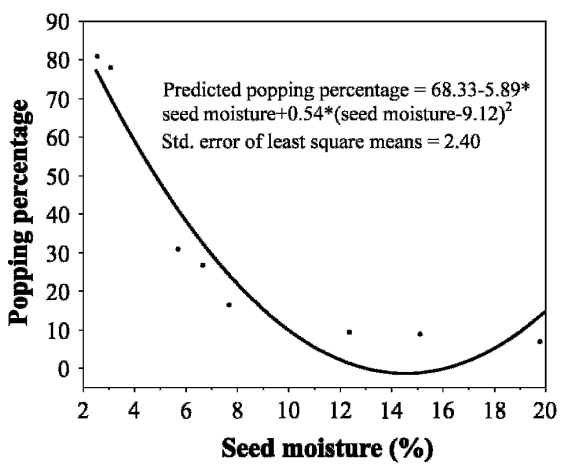

Fig. 1. Curvilinear decrease in popping percentage (least square means, arcsine ${ }^{-1}$ transformed data) with increasing seed moisture percentage in nuña bean breeding line 'PB24'. and one for moisture analysis. These bags were allowed to equilibrate for 6 weeks. The seeds of one sample bag in each moisture chamber were chosen at random and coarsely ground using a mortar and pestle. Three- to 4-g samples were weighed in predried aluminum weighing dishes and dried in a convection oven for $24 \mathrm{~h}$ at $100{ }^{\circ} \mathrm{C}$. Moisture content was calculated as the percentage of predried seed weight (Spaeth et al., 1989; van Beem and Spaeth, 1990).

Data analysis. A sample of 50 seeds from each replication and factorial level was popped and the percentage of fully popped seed was calculated. A seed was considered fully popped when the cotyledons had expanded sufficiently to shed the seedcoat and lacked a mottled appearance. For purposes of the analysis of variance, popping percentage data were transformed using arcsine ${ }^{-1}$ and levels of the three factorial treatments were considered random effects. Means for each level of a factorial treatment adjusted for the other effects in the model (least mean squares) were estimated. Graphs and contour plots are presented using untransformed data to facilitate interpretation of the results. The data were analyzed using the Standard Linear Models procedure of JMP statistical software (SAS Institute, Inc., Cary, NC). Single degree-of-freedom orthogonal contrast for factorial levels of treatments were calculated using PROC IML (SAS/IML Software, 1989).

\section{Results and Discussions}

The main effects, first- and second-order interactions associated with the three factorial treatments popping time, chamber temperature, and seed moisture were significant (Table 1). The main effects with the largest mean squares were seed moisture and chamber temperature, which were $\approx 20$ times larger than the mean square associated with popping time (Table 1 ).

Popping percentage decreased as seed moisture content increased (Table 1; Fig. 1). Nuña beans pop as a result of the buildup and release of steam pressure within the cellular structure of the cotyledons (Spaeth et al., 1989). The rate of mass transfer of steam is similar to that of heat (Toledo, 1991); thus, the observed results may be the result of greater steam channeling by mass transfer within the mesophyll of the cotyledons of lower compared with higher moisture content of nuña bean seeds. In higher moisture content (greater than 5\%) nuña bean seeds, steam was observed escaping from the surface of unpopped seeds. Thus, the reduced popping percentage of higher moisture content nuña bean seed may also be the result of the effect of the latent heat of steam formation and adiabatic cooling resulting from the escape of moisture from within the seed. The results of this study indicate that a seed moisture content less than $5 \%$ is optimal for successful popping.

An increase in popping percentage was observed with increasing chamber tempera- ture (Table 1; Fig. 2). Higher temperatures may produce larger amounts of steam within the mesophyll cells of the cotyledons of nuña bean seeds and more effectively bring the internal steam pressure above the deformation point of the cell walls. The results of this study indicate that chamber temperatures greater that $244{ }^{\circ} \mathrm{C}$ are optimal for successful popping.

Popping percentage increased with increasing popping time from 60 to $120 \mathrm{~s}$ (Table 1; Fig. 3). The curvilinear response indicated no increase in popping percentage after $90 \mathrm{~s}$ (Fig. 3). To avoid a burnt flavor of popped nuña beans, caution should be taken with combinations of cooking temperatures greater than $244{ }^{\circ} \mathrm{C}$ and cooking times longer than $90 \mathrm{~s}$, because undesirable scorching can result.

The largest magnitude first-order interaction was observed between seed moisture content and chamber temperature (Table 1). Popping percentages greater than $90 \%$ can be achieved with a seed moisture content of less than $5 \%$, a chamber temperature above 244 ${ }^{\circ} \mathrm{C}$, and cooking times of $90 \mathrm{~s}$ (Fig. 4). The optimal combination of seed moisture and chamber temperature may result in the water

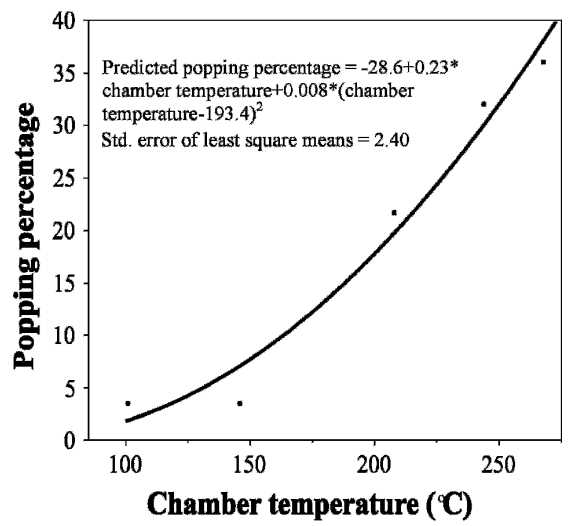

Fig. 2. Curvilinear increase in popping percentage (least square means, $\operatorname{arcsine}^{-1}$ transformed data) with increasing chamber temperature in nuña bean breeding line 'PB24'.

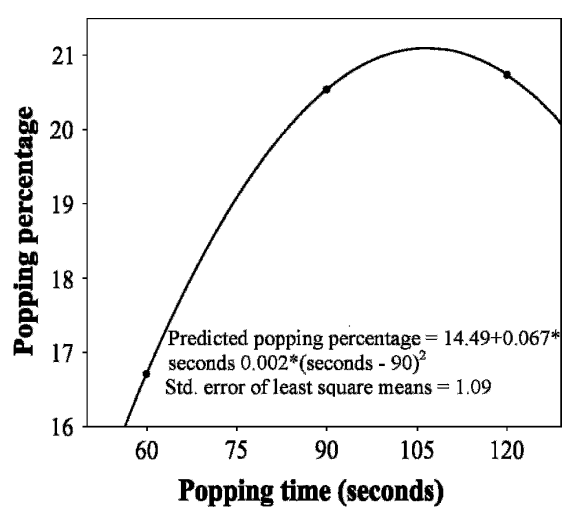

Fig. 3. Curvilinear increase in popping percentage (least square means, arcsine ${ }^{-1}$ transformed data) with increasing popping time in nuña bean breeding line 'PB24'. 


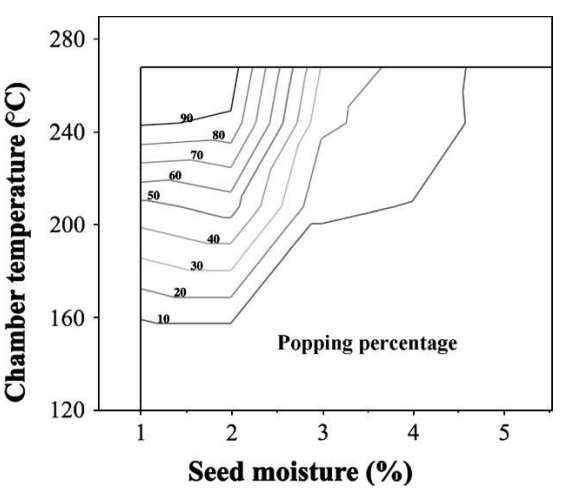

Fig. 4. Contour plot of popping percentage ( $\operatorname{arcsine}^{-1}$ transformed data) in nuña bean breeding line 'PB24' as a function of seed moisture content and chamber temperature. Data represent least square means adjusted for the effects of replications and popping time.

within the seeds achieving the vapor point in a shorter period of time, thus increasing popping and minimizing scorching. The relationship between seed moisture and popping temperature has also been observed in other popped products. In popcorn, low-moisture kernels pop at high temperatures and highmoisture kernels pop at lower temperatures (Lucas and Rooney, 2001). In puffed rice products, the rice is brought to a moisture content of $12 \%$ to $15 \%$ and fried in $220{ }^{\circ} \mathrm{C}$ oil; in contrast, rice with a $5 \%$ to $7 \%$ moisture is fried at 240 to $250{ }^{\circ} \mathrm{C}$ (Lucas and Rooney, 2001).

Consistent popping at or above $90 \%$ is important for successful commercialization of popped nuña beans. A high popping percentage allows for greater profitability, less waste, and less labor to remove undesir- able unpopped seeds from the product. Optimal popping was achieved in seeds with seed moistures below 5\%, chamber temperatures of $244{ }^{\circ} \mathrm{C}$ or higher, and popping times of $90 \mathrm{~s}$. Chamber temperatures of $244^{\circ} \mathrm{C}$ with a popping time of $90 \mathrm{~s}$ minimize the amount of seed carbonization resulting in a more desirable product. Future nuña popping research may focus on combinations of factors associated with the popping environment that may result in a further reduction of the level of carbonization of the popped product. In addition, in future research, greater attention should be paid to popping volume that may contribute to a more versatile and palatable snack food product and increased consumer acceptance.

\section{Literature Cited}

Bell, L.N. and T.P. Labuza. 2000. Moisture sorption: Practical aspects of isotherm measurement and use. 2nd Ed. AACC Egan Press, Egan, MN

Binning, L.K., C.M. Boerboom, L.G. Bundy, D. Curwen, E.T. Gritton, H.C. Harrison, H.J. Hopen, K.A. Kelling, S.E.R. Mahr, B.A. Michaelis, P.J. Schmidt, W.R. Stevenson, W.F. Tracy, J.L. Wedberg, and J.A. Wyman. 1995. Commercial vegetable production in Wisconsin. UWEX. Bul. A3422 Univ. of WI Press, Madison, WI.

Hoseney, R.C., K. Zeleznak, and A. Abdelrahman. 1983. Mechanism of popcorn popping. J. Cereal Sci. 1:43-52.

Kmiecik, K. and J. Nienhuis. 1997. Development of nuña beans with temperate zone adaptation Annu. Rpt. Bean Improv. Coop. 40:36-37.

Kmiecik, K. and J. Nienhuis. 1998. Recent notes and observations on: Standardization of popping and evaluations of nuña germplasm. Annu. Rpt. Bean Improv. Coop. 41:220.

Lucas, E.W. and L.W. Rooney (eds.). 2001. Snack foods processing. Technomic Publishing Co., Lancaster, PA.
McCurdy, A.R., H.K. Leung, and B.G. Swanson. 1980. Moisture equilibration and measurement in dry pinto beans (Phaseolus vulgaris). J. Food Sci. 45:506-508.

National Institute of Standards and Technology 2000a. Standard salt solutions for humidity calibration. Section 15:24. In: Lide, D.A. (ed.). CRC handbook of chemistry and physics. 77th Ed. CRC Press, LLC, Boca Raton, FL.

National Institute of Standards and Technology. 2000b. Constant humidity solutions. 15:25. In: Lide, D.A. (ed.). CRC handbook of chemistry and physics. 77th Ed. CRC Press, LLC, Boca Raton, FL.

National Research Council. 1989. Lost crops of the Incas. National Academy Press, Washington, DC.

SAS/IML Software. 1989. SAS/IML software: Usage and reference. 1st Ed. SAS Institute, Cary, NC.

Spaeth, S.C., D.G. Debouck, J. Tohme, and J. van Beem. 1989. Microstructure of nuñas: Andean popping beans (Phaseolus vulgaris L.). Food Microstruct. 8:263-269.

Tohme, J., O. Toro, J. Vargas, and D.G. Debouck. 1995. Variability in Andean nuña common beans (Phaseolus vulgaris Fabaceae). Econ. Bot. 49:78-95.

Toledo, R. 1991. Fundamentals of food process engineering. Aspen Food Science, Gaithersburg, MD.

van Beem, J., J. Kornegay, and L. Lareo. 1992. Nutritive value of nuña popping bean. Econ. Bot. 46:164-170.

van Beem, J. and S.C. Spaeth. 1990. Popping in nuña beans (Phaseolus vulgaris Fabaceae) grown outside traditional areas. Econ. Bot. 44:133-135.

Weston, W.J. and H.J. Morris. 1954. Hygroscopic equilibria of dry beans. Food Technol. 8:353355.

Zimmer, K.S. 1992. Biological diversity and local development: 'Popping beans' in the Central Andes. Mt. Res. Dev. 12:47-61. 